\title{
Sepsis in Pediatric Cancer: Does Gender Matter? A 20-Year Retrospective Study
}

\author{
Andreas Meryk - Gabriele Kropshofer - Caroline Bargehr • \\ Miriam Knoll • Benjamin Hetzer • Cornelia Lass-Flörl • \\ Roman Crazzolara (D)
}

Received: August 19, 2021 / Accepted: October 8, 2021 / Published online: October 25, 2021

(C) The Author(s) 2021

\section{ABSTRACT}

Introduction: Gender plays an active role in the incidence and outcome of many infectious and malignant diseases. However, there is still no study examining sex differences for developing bloodstream infections (BSIs) in pediatric patients with cancer. We sought to identify potential gender-specific risk factors for BSIs.

Methods: Data were retrospectively analyzed from 621 pediatric patients treated for childhood cancer in a tertiary single center between 1 January 2000 and 31 June 2018. After central venous access device (CVAD) placement, patients were followed up until CVAD was removed or at the most for 1 year. We calculated the gender-specific prevalence for BSIs and compared the causative bacterial strains.

Results: Of 621 pediatric patients with cancer (283 girls [45.6\%] and 338 boys [54.4\%]), 110 patients (41 girls [37.3\%] and 69 boys [62.7\%]) were identified with a total of 134 BSIs. Girls and boys had a similar incidence for BSI (13\%)

Andreas Meryk and Gabriele Kropshofer contributed equally and are co-first authors.

A. Meryk - G. Kropshofer - C. Bargehr · B. Hetzer · R. Crazzolara $(\varangle)$

Department of Pediatrics, Medical University of Innsbruck, Anichstrasse 35, 6020 Innsbruck, Austria e-mail: roman.crazzolara@i-med.ac.at

M. Knoll · C. Lass-Flörl

Institute of Hygiene and Medical Microbiology,

Medical University of Innsbruck, Innsbruck, Austria within the first 3 months of therapy, after which the risk for BSI increased significantly for boys $(34 \%$ versus $21 \%$, boys versus girls, $P=0.025)$. Moreover, BSI with gram-positive bacteria affected boys nearly twice as often as girls (29.8\% versus $56.5 \%$, girls versus boys).

Conclusions: Future clinical awareness of hygiene-related BSIs in boys could be helpful in identifying areas for improvement.

Keywords: BSI; Childhood cancer; Sex disparity

\section{Key Summary Points}

\section{Why carry out this study?}

Gender plays an active role in many infectious and malignant diseases.

No study has so far investigated genderspecific risk factors for bloodstream infections (BSIs) in pediatric patients with cancer.

\section{What was learned from the study?}

Boys have a significant increased risk for BSIs with hygiene-related pathogens, not at the early stage but 3 months following therapy onset.

The clinical awareness of gender-specific disparities may help to improve future cancer therapy. 


\section{INTRODUCTION}

Sex differences in the incidence and mortality of adult cancer are well established [1]. Similarly, gender differences in non-malignant diseases including infections are attributed to hormonal, immunological, or behavioral differences [2]. Even in early childhood, where these differences would not be entirely relevant, there is a male predominance for cancer [3], but to date no study has explicitly tested for sex differences in cancer-related risk of developing BSIs in pediatric patients. This is an important question because understanding the disparities may permit more complex reasoning, access to medical care, response to treatment, or a combination of these in future therapy plans. The objective of this study was to report the influence of gender on developing BSIs during active cancer therapy in pediatric patients.

\section{METHODS}

\section{Compliance with Ethics Guidelines}

The Ethics Committee of the Medical University of Innsbruck approved retrospective evaluation (EC No. 1301/2020) and also waived the need for patient consent because of its retrospective nature. All data were obtained from medical records. This study was performed in accordance with the Declaration of Helsinki.

\section{Patients and Data Collection}

All oncologic pediatric and adolescent patients below age 18 years, who were treated with chemotherapy at our center between 1 January 2000 and 30 June 2018 and who needed a longterm central venous access device (CVAD), were retrospectively analyzed in the study. A total of 621 patients were included and for the major group of patients with acute lymphoblastic leukemia and acute myeloid leukemia (more than $40 \%$ ) further details of the chemotherapy regimens were previously described [4]. After
CVAD placement, patients were followed up until the end of active cancer therapy (defined by CVAD explanation) or at the most for 1 year. Data in electronic records were analyzed and included baseline demographic information, baseline pathology, type and duration of CVAD use, microbiological diagnostic and therapeutic treatment as well as complications and side effects. Catheter-related BSIs were defined as clinical manifestations of infection with signs of sepsis and that the same organism grows from at least two quantitative blood cultures obtained through two different catheter lumens, according to the National Healthcare Safety Network (NHSN) definitions [5]. A detailed description of the patients, treatment characteristics, and pathogens was recently published [6].

\section{Statistical Analysis}

Descriptive statistics were performed for all variables of interest, giving medians and interquartile ranges for quantitative variables, and absolute and relative frequencies for qualitative variables. The chi-squared test was used for categorical variables and the Mann-Whitney $U$ test for continuous variables. The risk of BSI was assessed via Kaplan-Meier curves and compared with the log-rank test. Univariate and multivariate analyses were completed with Cox proportional hazards regression tests. Data analysis and visualization were performed with IBM SPSS Statistics, version 24.

\section{RESULTS}

Among 621 pediatric patients (283 girls [45.6\%] and 338 boys [54.4\%]) treated for cancer, we identified 110 patients (41 girls [37.3\%] and 69 boys [62.7\%]) who suffered 134 BSIs. Girls and boys had a similar incidence for BSI (13\%) until day 110 , after which the risk for BSI increased significantly for boys (34\% versus $21 \%$, boys versus girls, Fig. $1, P=0.025)$. Baseline characteristics, including age, pubertal status, and cancer type, were similar for girls and boys 


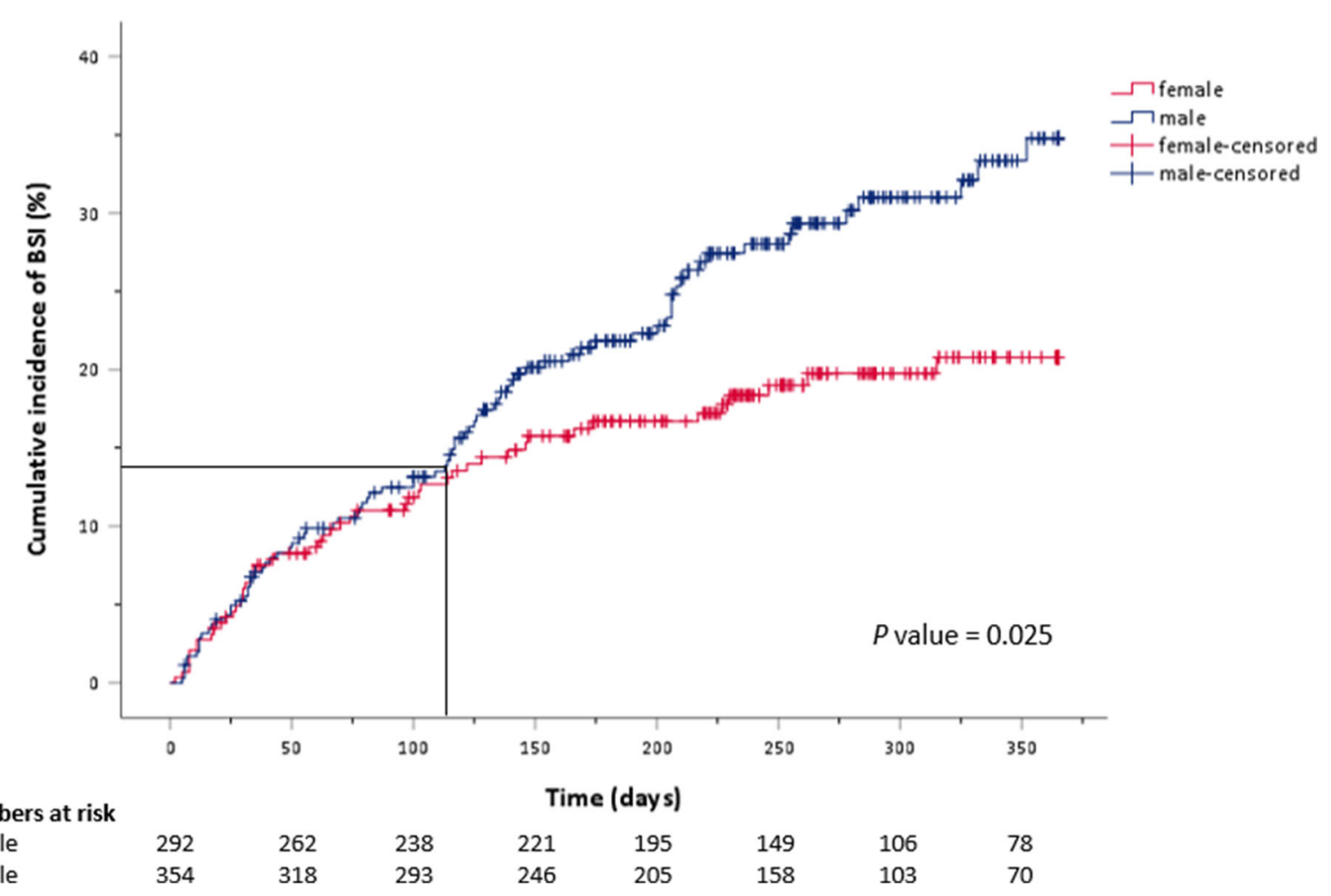

Fig. 1 Cumulative incidence of BSI. Since 2000, 621 pediatric patients (283 girls, 338 boys) were treated for cancer; 110 patients suffered 134 BSIs. The log-rank test was used to compare the risk for BSI between girls and boys $(P=0.025)$

(Table 1). The multivariate proportional hazard Cox regression analysis confirmed that male patients [hazard ratio (HR) $1.461 ; 95 \%$ CI 1.026-2.082; $P=0.04$ ] were at higher risk for BSIs. Additionally, the risk for BSIs was significantly lower for patients with solid tumors than with hematologic malignancies (HR 0.482; 95\% CI $0.332-0.700 ; \quad P<0.001)$. The isolated pathogens causing BSI differed significantly between the genders (Table $1, P=0.026$ ). Gramnegative bacteria were the most commonly isolated entity in girls (36.2\% versus $18.8 \%$, girls versus boys, Table $1, P=0.026)$, whereas boys suffered a BSI with gram-positive bacteria nearly twice as often as did girls (29.8\% versus $56.5 \%$, girls versus boys, Table $1, P=0.026$ ). Independently of the causative pathogens, girls had higher CRP (C-reactive protein) peaks than boys did (Table 1, $P=0.003$ ).

\section{DISCUSSION}

Although long-term survival in children with cancer now exceeds $80 \%$, BSIs represent the most frequent and life-threatening adverse events [7]. Our study demonstrates that girls and boys had a similar probability of BSIs during the first months of therapy, a time which is mostly accompanied by intensified cytotoxic treatment during hospitalization. However, boys more often suffered BSIs at later times, from the third to fourth month following the onset of cancer therapy. Gender-related vulnerability with male predominance for infections has been observed by analysis of general hospital admission and is often linked to hormonal variations, especially that of puberty $[8,9]$. Thus, we emphasize the importance of evaluating whether sex hormones might influence our observation. In our cohort, we performed multivariate analysis with Cox proportional hazards regression to calculate the impact of age and puberty at diagnosis on the 
Table 1 Patients' characteristics

\begin{tabular}{lccc}
\hline Characteristics & Female & Male & $P$ value \\
\hline Patients with BSI, no. (\%) & $41(37.3 \%)$ & $69(62.7 \%)$ & \\
No. & $7.14(1.9-11.1)$ & $7.36(3.6-12.8)$ & 0.390 \\
Age at diagnosis, median (IQR), years & $9(22.0 \%)$ & $21(30.4 \%)$ & 0.334 \\
Puberty at diagnosis & $29(70.7 \%)$ & $45(65.2 \%)$ & 0.551 \\
Non-solid tumor & & & \\
Cases with BSI ${ }^{\mathrm{a}}$ no. (\%) & $89(36.6 \%)$ & $62(73.8 \%)$ & 0.189 \\
No. & $41(83.7 \%)$ & $9.98(6.0-19.4)$ & 0.003 \\
WBCs $<1$ G/L & $17.88(10.0-25.6)$ & & \\
CRP peak, median (IQR), mg/dL & $17(36.2 \%)$ & $16(18.8 \%)$ & 0.026 \\
BSI with & $14(29.8 \%)$ & $48(56.5 \%)$ & $8(9.4 \%)$ \\
Gram-negative & $7(14.9 \%)$ & $13(15.3 \%)$ & \\
Gram-positive & $9(19.1 \%)$ & & \\
Non-fermenting & & \\
Polyinfection &
\end{tabular}

BSIs bloodstream infections, CRP C-reactive protein, $W B C$ white blood cells

${ }^{a}$ Two cases with unknown pathogen and in one case leukopenia and CRP are missing. $P$ value calculated using chi-square for categorical variables and Mann-Whitney $U$ test for age and CRP peak as continuous variables

development of BSI. Both factors were not significantly associated: age (HR 0.999; 95\% CI $0.943-1.059 ; P=0.98$ ) and puberty at diagnosis (HR 1.05; 95\% CI $0.529-2.087 ; \quad P=0.88$ ). Moreover, as basic characteristics (e.g., age, cancer type) were similar between genders and thus hormonal influence might be irrelevant, there could be another reason for our observed sex disparity. Male gender is typically associated with poor hygiene behavior, which is often illustrated by infections with gram-positive bacteria, for instance Staphylococcus aureus [10]. In our cohort, gram-positive bacteria caused BSIs two times more often in boys than in girls, and eight of nine BSIs with $S$. aureus occurred in boys. Thus, the onset of BSI and the causative pathogens in our cohort study highlighted the need for better hygiene education or at least an awareness of this gender-related issue. Limitations of this report include its retrospective nature, the fact that it was limited to a single center, and the potential for missing data.

\section{CONCLUSION}

The awareness and understanding of genderspecific disparities may permit further improvement of cancer therapy. We demonstrated that boys have an increased risk for BSIs with ongoing therapy duration associated with hygiene-related pathogens.

\section{ACKNOWLEDGEMENTS}

Funding. Sponsorship for this study and Rapid Service Fee were funded by grants from "Kinderkrebshilfe Tirol und Vorarlberg" and "Kinderkrebshilfe Südtirol-Regenbogen". 
Authorship. All named authors meet the International Committee of Medical Journal Editors (ICMJE) criteria for authorship for this article, take responsibility for the integrity of the work as a whole, and have given their approval for this version to be published.

Author Contributions. RC, AM, GK, and CLF designed the study. $\mathrm{BH}$ and $\mathrm{CB}$ collected the data. AM, MK, and RC analyzed the data. $\mathrm{AM}$ and RC wrote the manuscript. All authors reviewed, revised, and approved the final version of the manuscript.

Disclosures. Andreas Meryk, Gabriele Kropshofer, Caroline Bargehr, Miriam Knoll, Benjamin Hetzer, Cornelia Lass-Flörl, and Roman Crazzolara have nothing to disclose.

Compliance with Ethics Guidelines. The Ethics Committee of the Medical University of Innsbruck approved the retrospective evaluation (EC No. 1301/2020). All data were obtained from medical records. This study was performed in accordance with the declaration of Helsinki. The IRB/ethics committee waived the need for patient consent because of its retrospective nature.

Data Availability. The datasets generated during and/or analyzed during the current study are available from the corresponding author on reasonable request.

Open Access. This article is licensed under a Creative Commons Attribution-NonCommercial 4.0 International License, which permits any non-commercial use, sharing, adaptation, distribution and reproduction in any medium or format, as long as you give appropriate credit to the original author(s) and the source, provide a link to the Creative Commons licence, and indicate if changes were made. The images or other third party material in this article are included in the article's Creative Commons licence, unless indicated otherwise in a credit line to the material. If material is not included in the article's Creative Commons licence and your intended use is not permitted by statutory regulation or exceeds the permitted use, you will need to obtain permission directly from the copyright holder. To view a copy of this licence, visit http:// creativecommons.org/licenses/by-nc/4.0/.

\section{REFERENCES}

1. Sung H, Ferlay J, Siegel RL, et al. Global cancer statistics 2020: GLOBOCAN estimates of incidence and mortality worldwide for 36 cancers in 185 countries. CA Cancer J Clin. 2021;71:209-49.

2. Klein SL, Flanagan KL. Sex differences in immune responses. Nat Rev Immunol. 2016;16(10):626-38.

3. Williams LA, Richardson M, Marcotte EL, Poynter JN, Spector LG. Sex ratio among childhood cancers by single year of age. Pediatr Blood Cancer. 2019;66(6):e27620.

4. Meryk A, Kropshofer G, Hutter J, et al. Benefits of risk-adapted and mould-specific antifungal prophylaxis in childhood leukaemia. Br J Haematol. 2020;191:816-24.

5. Mermel LA, Allon M, Bouza E, et al. Clinical practice guidelines for the diagnosis and management of intravascular catheter-related infection: 2009 update by the Infectious Diseases Society of America. Clin Infect Dis. 2009;49(1):1-45.

6. Meryk A, Kropshofer G, Bargehr C, et al. Which type of empiric antibiotic therapy is appropriate? A 20-year retrospective study of bloodstream infections in childhood cancer. Infect Dis Ther. 2021;10:789-800.

7. O'Connor D, Bate J, Wade R, et al. Infection-related mortality in children with acute lymphoblastic leukemia: an analysis of infectious deaths on UKALL2003. Blood. 2014;124(7):1056-61.

8. Watson RS, Carcillo JA, Linde-Zwirble WT, Clermont G, Lidicker J, Angus DC. The epidemiology of severe sepsis in children in the United States. Am J Respir Crit Care Med. 2003;167(5):695-701.

9. Tasker RC. Gender differences and critical medical illness. Acta Paediatr. 2000;89(5):621-3.

10. Humphreys H, Fitzpatick F, Harvey BJ. Gender differences in rates of carriage and bloodstream infection caused by methicillin-resistant Staphylococcus aureus: are they real, do they matter and why? Clin Infect Dis. 2015;61(11):1708-14.

\section{Publisher's Note}

Springer Nature remains neutral with regard to jurisdictional claims in published maps and institutional affiliations. 